\title{
"Thinking beyond your own fence line": subdivision and land use tensions in Pohangina Valley, near Palmerston North
}

\author{
P. BLACKETT, H. ROTH ${ }^{1}$, J. BROCK ${ }^{2}$ and T. PARMINTER \\ AgResearch, Ruakura Agricultural Centre, Private. Bag 3123, Hamilton \\ ${ }^{1}$ Omega Consulting Ltd, PO Box 4699, Mount Maunganui. \\ ${ }^{2}$ R. D. 14, Ashhurst, Manawatu \\ paula.blackett@agresearch.co.nz
}

\begin{abstract}
In Pohangina Valley, near Palmerston North, subdivision over the last 30 years has created a mix of large sheep, beef, dairy and deer farms, lifestyle blocks and village housing lots. For the Valley, like many other New Zealand rural communities, this has lead to a diversity of perspectives and tensions between some residents over subdivision and land use. A number of these issues were exposed at a workshop held as part of a "Project Pohangina" Community Conference. Key issues for participants were a desire to maintain the Valley's beauty, natural features and views, keep population density synchronised with available infrastructure, restrain ad hoc subdivision and buildings, control weeds, pests and unlimited tree plantings, protect farm profitability and maintain private property rights. Identification and reconciliation of these potentially conflicting goals by rural communities highlights some of the challenges of maintaining a vibrant community in a productive farming landscape.
\end{abstract}

Keywords: subdivision, rural communities, land use tensions

\section{Introduction}

A general economic downturn was experienced by rural New Zealand during the late 1970s and 1980s as a result of a global recession and socio-economic change (Wilson 1995; Joseph et al. 2001). At the community level, this translated into lower farm spending, reduced rural employment and business opportunities, and an erosion of rural services and infrastructure. Moreover, people left the country for the city (LeHeron \& Pawson 1996). To counter population decline in the Pohangina Valley the Local Authority (Pohangina County Council at this time) decided to relax the rules on subdivision as a way of promoting "lifestyle" blocks to try and rejuvenate the area (McHardy, 2006).

The 1982 District Scheme produced by the Local Authority was successful in attracting lifestylers to the area (in that the population has doubled in the last 20 years), but the scheme lacked clarity and was redefined in 1995 by the Manawatu District Council as part of the District Plan under the Resource Management Act 1991 (RMA). Revision of subdivision rules had to be considered carefully in light of the classification of the Pohangina Valley as an 'outstanding natural landscape' by the Regional Council. This meant under Section 6 of the RMA that the Valley had to be protected from "inappropriate subdivision, use and development". In the Manawatu District Plan, this is manifested as additional controls on subdivision designed to protect the character of the area (P. McHardy pers. comm.). New rules revolve primarily around restricting the proximity of new dwellings rather than addressing any impacts on the overall landscape.

Valley Residents highly value the views of the Ruahine Ranges and Pohangina River, afforded to them by living in the Valley, and wish to retain the natural character of the area. However, parallel to this desire, is a wish to retain and improve community spirit and vibrancy brought about by a larger rural population and match expansion to available infrastructure (Roth et al. 2005; Parminter et al. 2005). On initial inspection these goals appear to be in complete conflict and hold the potential to divide the Valley. This paper seeks to further explore the tensions brought about by increased subdivision in the Pohangina Valley and make more explicit the trade-offs and challenges faced by this rural community.

\section{Methods}

This work is part of an ongoing MAF Sustainable Farming Fund project developing facilitation methods for, and researching the process of, the formation of a shared community vision which may contribute towards "Community Outcomes" as they are defined under the Local Government Act 2002 (Local Government Act 2002).

Information on community views and tensions over subdivision was collected during a 1 hour workshop as part of a Community Mini-Conference day on subdivision and infrastructure at Pohangina Hall on the 25 March 2006. The Conference was open to any person living in Pohangina Valley, and workshop attendees (36 in total) were a mix of sheep and beef farmers, lifestyle block owners and residents of Pohangina Village. Participants were asked to form groups ( $>$ eight people) and record what they considered the pros and cons of subdivision in Pohangina Valley from both a farmer/ 
landowner and a community perspective. Each group was asked to verbally report back to remaining participants to explain their views and concerns (methods after Carman \& Keith (1994)). This session was recorded for transcription and written material was collected for analysis.

\section{Results}

\section{Similarities in perspectives}

Participants identified quite a number of similarities in the pros and cons of subdivision between farmers/ landowners and community perspectives in the Pohangina Valley (Table 1). These revolved primarily around maintaining a vibrant and active diverse community, the potential for infrastructure upgrades (schools, roads etc) and more employment opportunities. However, each of these positives had associated problems. For example, with greater social diversity there is more tension between competing values and interests, and the current infrastructure may be stretched with more newcomers. Many residents believed current infrastructure, and particularly the roads are already unsuitable for current traffic volumes. In addition, there were concerns about less privacy and the effect on community spirit of lifestyle blocks with a high owner turnover rate. Another concern was the visual effects on the landscape from additional homes and the land use choices of the small block owners (e.g. shelter belts or forestry planting). Participants were worried that newcomers may lack knowledge on animal care and population increases could force farmers to meet additional rules (e.g. put in stock crossings).

Land prices appeared as both pros and cons because they represent capital gain for existing residents but participants were worried that high land price increases might attract speculators to purchase and subdivide. Moreover, with high land prices, it may become more profitable to subdivide than continue farming.

\section{Community perspectives}

There was recognition that a greater population density may increase lobbying power on local authorities and could lead to the community having an influence on subdivision policy (Table 2). In addition, with each subdivision the community may benefit from reserve contributions or increased access to a desirable area. Concerns about subdivision focused around a perceived increase in rubbish, more pressure on the environment, a loss of personal freedoms and a feeling that some subdivisions are undertaken with little hint of any long term plan. A sore point was that the community was seldom given any chance to comment on any proposed plan.

\section{Landowners/ Farmers perspectives}

For landowners, subdivision creates a cash flow and may allow them to remove marginal land from production or finance other business or personal possibilities (Table 3 ). More people create a greater market for firewood and anyone subdividing can design a plan to best suit the environment. On the downside, new neighbours, unfamiliar with country ways, may fail to control pests and weeds or complain about normal farming practices and there could be increasing public pressure to open the farm for public access.

Table 1 Pros and cons of subdivision in the Pohangina Valley that were identified by workshop participants and which were common to both farmers/landowners and the community.

\section{Pros}

Rejuvenates communities - more people

maintains School, School Bus, Local Hall, Church, social activities

Social/cultural diversity

Potential for more infrastructure, Roading, Sceptic, Water, School Telecommunications

Advantage for certain businesses and more employment opportunities and employees available

Elevation of land prices Attracts exploitation by non residents [neither land owners nor community]

Increases value of land so that some land uses become unviable - e.g., pastoral farming becomes uneconomic

\section{Cons}

Don't know all your neighbours any more Moved out here to get away from people! Subdivision sprawl

Less privacy

Pressure on existing infrastructure increases, traffic, waste services Land-price increase

Visual 'pollution' - Landscape affectedLoss of quality of lifestyle e.g., views, roads, traffic

High rotation, turnover of lifestylers

Noise

Animal welfare knowledge may be lacking in newcomers

Farmers will have more requirements to meet for example, Stock crossings Stock loading

Increased dog population - marauding dogs 
Table 2 Pros and cons of subdivision in the Pohangina Valley from a community perspective as identified by workshop participants.

\begin{tabular}{ll}
\hline Pros & Cons \\
\hline More influence on policy matters & $\begin{array}{l}\text { General increase in pollution - beer cans, plastic } \\
\text { bags }\end{array}$ \\
$\begin{array}{l}\text { New subdivisions may give the community } \\
\text { chance to }\end{array}$ & $\begin{array}{l}\text { Little consultation or planning regarding } \\
\text { development }\end{array}$ \\
$\begin{array}{l}\text { a) Place covenants on bush areas of community } \\
\text { value ('Reserve Contribution' as part of }\end{array}$ & Disagreements over different interests and \\
subdivision) & values \\
b) Achieve consistent standards & Regulations increase (loss of freedom) \\
& Increased pressure on environment \\
\hline
\end{tabular}

Table 3 Pros and cons of subdivision in the Pohangina Valley from a farmer/landowners perspective as identified by workshop participants.

\begin{tabular}{ll}
\hline Pros & Cons \\
\hline $\begin{array}{l}\text { Land asset increases - can borrow more dollars } \\
\text { for development, sell up for capital gain }\end{array}$ & $\begin{array}{l}\text { Inappropriate areas (highly productive land) being } \\
\text { subdivided - no grand plan or thought just } \\
\text { haphazard development } \\
\text { Allows subdivision of marginal land and could } \\
\text { represent best utilisation of land }\end{array}$ \\
$\begin{array}{l}\text { Ignorance of country ways e.g. dog control, } \\
\text { farming practices }\end{array}$ \\
$\begin{array}{l}\text { Release of capital } \\
\text { Land owner can control subdivision using } \\
\text { covenants and innovative design }\end{array}$ & $\begin{array}{l}\text { Reserves, Rights of Way) } \\
\text { Pest, disease and weed control issues and lack } \\
\text { of control over neighbours practices }\end{array}$ \\
& Forestry: Pruning and plantings \\
\hline
\end{tabular}

\section{Discussion}

\section{The infrastructure question}

The decline of services and infrastructure in rural New Zealand as a result of deregulation over the last few decades is well described (LeHeron \& Pawson 1996; Joseph et al. 2001; Chalmers \& Joseph 1994). Dissatisfaction with rural service provision was clearly expressed in Pohangina but was also considered a disadvantage of rural living by participants in Cook and Fairweather's (2005) national survey of small holdings. A key concern for Pohangina residents is to ensure infrastructure and services in the Valley expand to match population growth. At present rural communities have very little control over this balance because the decision to subdivide is subject to market demands whereas the level of infrastructure depends on District Council priorities and funding for roads, the Ministry of Education policy for schools and commercial decisions for power supply and telecommunications. There is opportunity for a clear misalignment of community goals and economic drivers if subdivision outstrips infrastructure upgrades, as appears to be occurring in Pohangina Valley. In reality, the only current option any community has to effect infrastructure change is through lobbying appropriate decision makers.

\section{Private property rights versus community interest}

There are a number of issues in Pohangina Valley, which highlight conflicts between individual benefits and community interest.

Firstly, there is general agreement that landowners ought to be able to subdivide their property to release funds as desired. However, participants thought it should be confined to appropriate marginal lands (excluding erosion or flood prone areas) not productive areas, which if lost could encroach on farm viability. As successful profitable farms are linked to local economies and the New Zealand economy overall (LeHeron \& Pawson 1996), loss of productive land to urban or periurban sprawl has become an increasingly sensitive issue. Market forces appear to be supporting lifestyle blocks rather than farm units across the country. More importantly is the belief that the community should have some sort of say in how blocks are designed and where subdivision occurs. Under the District Plan, compliant subdivisions are permitted non-notified activities, which mean locals may not be aware of events until consents are granted. This approach may not facilitate consideration of cumulative impacts of subdivision within the Valley (Peterson 1999). To allow residents a significant say over what subdivisions occur clearly 
invites the NIMBY (not in my backyard) principle but some variation on design might reduce the "visual pollution" and could be investigated. A number of developers in other districts have created clustered rural housing rather than blocks and this may represent some form of compromise.

Secondly, residents are torn between wanting to maintain a strong diverse community, which will ensure the local school, café and church are retained and other services are upgraded (roads, mobile phone coverage and power supply), while avoiding further effects on landscape values and existing Valley culture. The complete lack of control over landscape and land use changes, which may have an impact on a valued view of the Valley, is a considerable source of frustration for many people. In particular, the planting of pine plantations and shelterbelts creates tension because of the impacts on sunlight and views. As a result there is a desire to have some measure of control over activities on private property. In other words, new people would be welcome in the Valley but it would be preferred if they conformed to a set of "good neighbour" guidelines based around understanding of existing landscape values and Valley culture. This seems to revolve primarily around aspects such as managing pests and weeds and having limited visual effects on other residents. As noted by Swaffield and Fairweather (1998) rural residents, particularly lifestyle block owners, are becoming increasingly vocal over protecting their expectations and ideals of the rural environment.

\section{Resolving the tensions - from here to where?}

Subdivision is a double-edged sword for rural communities, like Pohangina Valley, because of the mixed bag of benefits and costs associated with a higher rural population. There are several clear tensions here between economic drivers to subdivide (which are not abating) and the desire to attain a vibrant well-serviced community and maintain landscape values. Attempts to align the often conflicting goals and aspirations will need to engage local authorities, the community and organisations with economic directives in a debate over how to move towards more sustainable rural communities.

The next step in "Project Pohangina" addresses these issues by employing a method that promotes community debate and discussion of goals and highlights the tradeoffs and linkages between different desired outcomes (Parminter et al. 2005). Although the researchers will facilitate the process they will not be involved in the debate. Issues that will need addressing include how much say should the community have over issues on private property, and what people are willing to sacrifice. Of great importance is addressing how, when and by whom, community aspirations can be furthered with appropriate decision markers. The mostly likely scenario is promoting community aspirations through the District Council Community Outcomes process (under the Local Government Act) with effective lobbying to influence the District Plan.

\section{ACKNOWLEDGEMENTS}

Lyn Hanes for typing the workshop data; Sustainable Farming Fund; Valley residents for participating in the workshop; two anonymous reviewers for their helpful comments.

\section{REFERENCES}

Carman, K.; Keith, K. 1994. Community consultation techniques: purposes, processes and pitfalls. A guide for planners and facilitators, Queensland Department of Primary Industries.

Chalmers, L.; Joseph, A. 1994. Changes in the rural communities of the Waikato. In: Proceedings of the 17th New Zealand Geographical Society Conference, 1993. NZGS.

Cook, A.J.; Fairweather, J.R. 2005. Characteristics of smallholdings in New Zealand: results from a nationwide survey. Research Report 278 Agribusiness and Economics Research Unit, Lincoln University.

Joseph, A.E.; Lidgard, J.M.; Bedford, R. 2001. Dealing with ambiguity: on the interdependence of change in agriculture and rural communities. New Zealand Geographer 57: 16-26.

LeHeron, R.; Pawson, E. 1996. Changing places: New Zealand in the nineties. Longman Paul, Auckland.

Parminter T.G., Brock J.L; Hein R. 2005. Pohangina Valley and community development. In: Proceedings of the International Conference on Engaging Communities, Brisbane. In Press.

Peterson, R. 1999. Environmental impact assessment of small scale activities. Centre for Impact Assessment Reserch and Training, Department of Geography, Univeristy of Otago, Dunedin.

Swaffield, S.; Fairweather, J. 1998. In search of Arcadia: the persistence of the rural idyll in New Zealand rural subdivisions. Journal of Environmental Planning and Management 41: 111-127.

Wilson, O.J. 1995. Rural restructuring and agriculture rural economy linkages: a New Zealand case study. Journal of Rural Studies 11: 417-431. 